\title{
Validity and Reliability of the Dutch Adaptation of the Actinic Keratosis Quality of Life Questionnaire (AKQoL)
}

\author{
Kelly Vis ${ }^{a}$ Rick Waalboer-Spuij ${ }^{a, b}$ Dyon G.C.T.M. Snels ${ }^{c}$ Loes M. Hollestein ${ }^{a} d$ \\ ${ }^{a}$ Department of Dermatology, Erasmus MC Cancer Institute, Rotterdam, The Netherlands; ${ }^{b}$ Department of \\ Dermatology, Elisabeth-TweeSteden Hospital, Tilburg, The Netherlands; ' ${ }^{\mathrm{C}}$ Department of Dermatology, Franciscus \\ Gasthuis and Vlietland, Rotterdam, The Netherlands; ${ }^{d}$ Netherlands Comprehensive Cancer Organization (IKNL), \\ Netherlands Cancer Registry, Eindhoven, The Netherlands
}

\section{Keywords}

Actinic keratosis · Health-related quality of life

\begin{abstract}
Background: The Actinic Keratosis Quality of Life Questionnaire (AKQoL) is a disease-specific instrument to measure the impact of actinic keratosis (AK) on patients' lives. Objective: To validate and test the psychometric properties of the AKQoL translated into the Dutch language (AKQoL-NL). Methods: All new patients $\geq 50$ years of age with untreated AK in a university medical center and a general hospital between August 2014 and August 2015 were eligible. The AKQoL was obtained and repeated after 2 weeks. The feasibility was tested by missing responses and response distribution. The internal consistency reliability of each domain was investigated with the Cronbach alpha, and test-retest reliability and validity with the Spearman correlation coefficient. AKQoL scores were compared to the Skindex-17 for convergent validity and to the Groningen Frailty Indicator scores for divergent validity. Results: A total of 153 of 190 eligible patients consented to participate. Feasibility analysis showed that none of the items missed $\geq 10 \%$ of responses but 5 of the 9 items showed floor effect. The AKQoL subscales showed a moderate internal consistency (Cronbach
\end{abstract}

\begin{tabular}{ll}
\hline KARGER & ( ) 2018 The Author(s) \\
Published by S. Karger AG, Basel Openger \\
E-Mail karger@karger.com & This article is licensed under the Creative Commons Attribution- \\
www.karger.com/drm & NonCommercial-NoDerivatives 4.0 International License (CC BY- \\
NC-ND) (http://www.karger.com/Services/OpenAccessLicense). \\
Usage and distribution for commercial purposes as well as any dis- \\
tribution of modified material requires written permission.
\end{tabular}

$a=0.235-0.468$ ) and an excellent test-retest reliability (interclass correlation coefficient $=0.997-1$ ). The AKQoL correlated poorly with the symptom component and moderately with the psychosocial component of the Skindex-17 ( $\rho=$ -0.015 to 0.346 and 0.324 to 0.501 , respectively), which is less than expected. The AKQoL scored poorly in both of the Groningen Frailty Indicator (GFI) components ( $\rho=-0.97$ to 0.12 and 0.185 to 0.276 , respectively), as expected. Conclusion: The AKQoL-NL is a feasible, moderately valid, and moderately reliable health-related quality of life questionnaire.

(C) 2018 The Author(s)

Published by S. Karger AG, Basel

\section{Introduction}

Actinic keratosis ( $\mathrm{AK}$ ) is an epidermal manifestation of abnormal keratinocyte proliferation caused by exposure to ultraviolet radiation. With an estimated prevalence of between 1.4 and $25 \%$ of the population [1-5], it is the most common premalignant condition in the Caucasian population.

K.V. and R.W.-S. contributed equally to this paper.
Rick Waalboer-Spuij

Department of Dermatology, Erasmus MC Cancer Institute Postbus 2040

NL-3000 CA, Rotterdam (The Netherlands)

E-Mail r.waalboer@erasmusmc.nl 


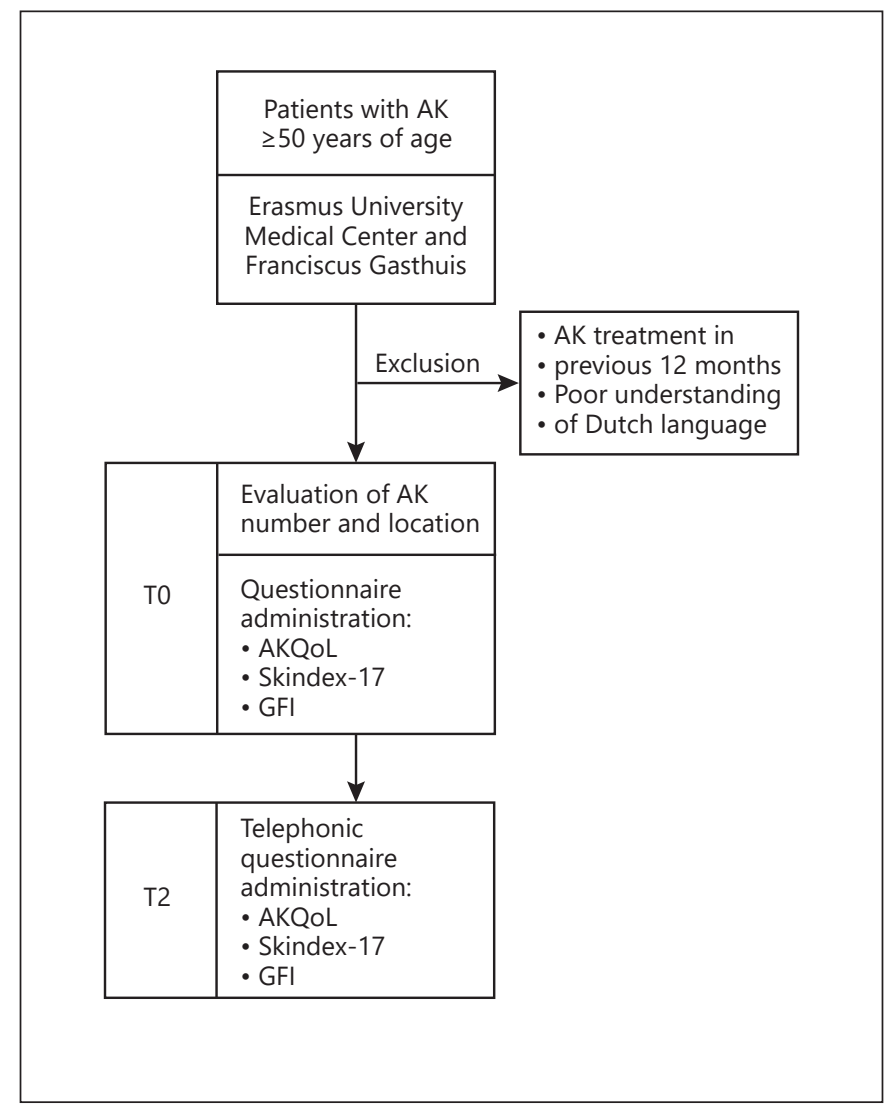

Fig. 1. Flowchart of Materials and Methods. AK, actinic keratosis; GFI, Groningen Frailty Indicator; T2, 2 weeks after the initial questionnaire.

AKs usually are present as scaly, red lesions which may adhere to clothing, itch, or bleed and can therefore cause an uncomfortable physical experience. They are mostly located on skin areas chronically exposed to ultraviolet radiation, such as the face, scalp and dorsal hands, thereby also causing cosmetic discomfort to the patient. Due to its premalignant nature the fear of developing skin cancer often arises, which could lead to anxiety and stress. Therefore, patients with AK may have health-related quality of life (HRQoL) impairment.

To determine the influence of dermatological diseases on this HRQoL, there are several instruments available [6, 7]. These are generic questionnaires and are used for a variety of diseases in dermatology, which makes it possible to compare the burden of different conditions. As they are not disease-specific they might miss important aspects that have a great impact on the quality of life of specific patient groups. Therefore, the AKQoL was developed in 2012.
Table 1. Patient characteristics

\begin{tabular}{ll}
\hline Male & $90(59)$ \\
Median age (IQR), years & $74(68-81)$ \\
Number of AKs & \\
$\quad 1-3$ & $52(34)$ \\
$4-9$ & $61(40)$ \\
$\quad \geq 10$ & $40(26)$ \\
Localization of AK & \\
$\quad$ Face (including ears) & $96(63)$ \\
Scalp & $29(19)$ \\
Other & $20(13)$ \\
Unknown & $8(5)$ \\
Questionnaire & $153(100)$ \\
$\quad$ First interview (test) & $146(95)$ \\
Interview after 2 weeks (retest) & \\
\hline
\end{tabular}

Values are $n(\%)$ unless otherwise indicated. AK, actinic keratosis.

It was the first disease-specific questionnaire for $\mathrm{AK}$, which was demonstrated to be valid and to have an excellent internal consistency, a high reproducibility, and a high responsiveness. It appears to be a valuable instrument for assessing improvement in patients' HRQoL in both clinical practice and trials [8].

Although the AKQoL has been frequently used, documenting and testing its psychometric properties has been limited to the Spanish $[9,10]$ and Danish populations (original study [8]). Therefore, the objective of this study is to test the psychometric properties of the Dutch version of the AKQoL (AKQoL-NL) in a heterogeneous group of Dutch patients diagnosed with AK.

\section{Materials and Methods}

For further details, see the online supplementary material (see www.karger.com/doi/10.1159/000489118 for all online suppl. material) [7, 11-18] (Fig. 1).

\section{Results}

\section{Study Population}

Of the 198 AK patients who were screened for inclusion, 190 were eligible, of whom 153 consented to participate (81\%). The other 37 declined due to lack of time or interest. The mean age of the participants was 75 years, almost $60 \%$ were men, and the most common AK local- 
Table 2. Internal consistency

\begin{tabular}{llr}
\hline Domain & Cronbach $\alpha$ & $95 \% \mathrm{CI}$ \\
\hline AKQoL-NL overall (total) & 0.643 & 0.552 to 0.722 \\
Emotion $(\mathrm{q} 2,4,6)$ & 0.468 & 0.303 to 0.599 \\
Function $(\mathrm{q} 1,8,9)$ & 0.297 & 0.080 to 0.470 \\
Control $(\mathrm{q} 5,7)$ & 0.235 & -0.053 to 0.444 \\
Global (q3) & not applicable & not applicable \\
\hline
\end{tabular}

AKQoL-NL, Dutch version of the Actinic Keratosis Quality of Life Questionnaire.

Table 3. Observed Spearman rank correlations between domains

\begin{tabular}{llllll}
\hline & $\begin{array}{l}\text { Dutch, } \\
\text { current study }\end{array}$ & 95\% CI & $\begin{array}{l}\text { Danish, } \\
\text { original study }{ }^{1}\end{array}$ & $\begin{array}{l}\text { Spanish, } \\
\text { validation study }{ }^{2}\end{array}$ & $\begin{array}{l}\text { Spanish, } \\
\text { validation study }^{3}\end{array}$ \\
\hline Emotion (function) & 0.373 & 0.226 to 0.523 & 0.530 & 0.652 & 0.777 \\
Control (function) & 0.396 & 0.254 to 0.519 & 0.427 & 0.533 & 0.566 \\
Control (emotion) & 0.412 & 0.267 to 0.549 & 0.622 & 0.568 & 0.570 \\
\hline
\end{tabular}

${ }^{1}$ Esmann et al. [8]. ${ }^{2}$ Longo Imedio et al. [9]. ${ }^{3}$ Alarcon et al. [10].

Table 4. Test-retest reliability

\begin{tabular}{llllr}
\hline Domain & Test score & Retest score & $\begin{array}{l}\text { Intraclass } \\
\text { correlation coefficient }^{1}\end{array}$ & 95\% CI \\
\hline Emotion & $0.94(1.10)$ & $0.94(1.11)$ & 0.997 & 0.996 to 0.998 \\
Function & $1.61(1.52)$ & $1.59(1.51)$ & 1.000 & 1.000 to 1.000 \\
Control & $1.04(1.08)$ & $1.03(1.09)$ & 1.000 & 1.000 to 1.000 \\
Global & $0.07(0.34)$ & $0.09(0.39)$ & 1.000 & - \\
\hline
\end{tabular}

Test and retest score values are mean (SD). ${ }^{1}$ One-way random effects model.

ization was the face. Most participants (95\%) were re-interviewed after 2 weeks (Table 1).

\section{Feasibility}

There were no missing data: all of the patients responded to all items. Floor effects $\geq 85 \%$ were found in items 2 , 3 (single-item subscale "global"), 5, 6, and 8 . No floor effects were found in the other subscales or in the total scale.

\section{Reliability}

The item responses of the first assessment of the domains of the AKQoL-NL showed a poor internal consistency (Cronbach $\alpha=0.235,0.297$, and 0.468) (Table 2). The correlations between domains were lower than those obtained in the original scale of Esmann et al. [8] and in the two Spanish validation studies (Table 3).

Validity and Reliability of the AKQoL-NL
The test-retest reliability (or "repeatability"), which was analyzed twice (2 weeks apart) among the 146 patients who completed the AKQoL, was excellent for all domains (Table 4).

\section{Validity}

Construct Validity. The AKQoL correlated poorly with both the SS and the PSS of the Skindex-17, which was used to test convergent validity (Table 5). The correlation with the domains of the GFI (divergent validity) were lower.

Discriminative Validity. The mean of the AKQoL total scores increased significantly with the severity of AK. The mean scores of patients with mild AK were $2.81(\mathrm{SD}=2.67), 3.31(\mathrm{SD}=2.63)$ for patients with moderate $\mathrm{AK}$, and $5.28(\mathrm{SD}=3.35)$ for patients with 
Table 5. Convergent and divergent validity: multitrait-multimethod correlation matrix using the Spearman correlation coefficient

\begin{tabular}{|c|c|c|c|c|}
\hline & \multicolumn{4}{|l|}{ AKQoL } \\
\hline & function & emotion & control & global \\
\hline Symptoms & $0.295^{* *}$ & $0.339^{* *}$ & $0.226^{* *}$ & 0.015 \\
\hline $95 \% \mathrm{CI}$ & 0.147 to 0.431 & 0.174 to 0.481 & 0.076 to 0.377 & -0.146 to 0.190 \\
\hline Psychosocial & $0.332^{* *}$ & $0.376^{* *}$ & $0.306^{* *}$ & $0.338^{* *}$ \\
\hline \multicolumn{5}{|c|}{ Divergent validity: GFI } \\
\hline Physical & 0.007 & -0.039 & -0.106 & -0.011 \\
\hline $95 \%$ CI & -0.147 to 0.160 & -0.195 to 0.118 & -0.262 to 0.055 & -0.186 to 0.168 \\
\hline Cognition & 0.084 & 0.001 & -0.005 & -0.051 \\
\hline $95 \% \mathrm{CI}$ & -0.065 to 0.217 & -0.149 to 0.131 & -0.156 to 0.158 & -0.077 to -0.025 \\
\hline Social & $0.170^{*}$ & $0.221^{* *}$ & 0.143 & $0.201^{*}$ \\
\hline
\end{tabular}

AKQoL, Actinic Keratosis Quality of Life Questionnaire. * Correlation is significant at the 0.05 level (2-tailed). ** Correlation is significant at the 0.01 level (2-tailed).

Table 6. Discriminative validity

\begin{tabular}{llll}
\hline AK severity & $\begin{array}{l}\text { AKQoL } \\
\text { total score }\end{array}$ & $\begin{array}{l}p \text { value } \\
\text { for trend }\end{array}$ & $\begin{array}{l}\text { Post hoc testing } \\
p \text { value }\end{array}$ \\
\hline Mild $(n=52)$ & $2.81(2.67)$ & $<0.001$ & 1.000 (vs. moderate) \\
Moderate $(n=61)$ & $3.31(2.63)$ & 0.003 (vs. severe) \\
Severe $(n=40)$ & $5.28(3.35)$ & \\
\hline
\end{tabular}

AKQoL total score value is mean (SD). Mild: 1-3 AKs; moderate: 4-9 AKs; severe: >10 AKs. AK, actinic keratosis; AKQoL, Actinic Keratosis Quality of Life Questionnaire.

severe AK (Table 6; $p<0.001$ ) with a significant difference between the moderate $\mathrm{AK}$ and severe $\mathrm{AK}$ groups in the post hoc testing.

\section{Discussion}

In this study, we tested the psychometric properties of the AKQoL-NL. Our data suggest that the questionnaire is feasible. The results on reliability were inconsistent: the internal consistency was poor, but the repeatability was excellent and inter-item and inter-scale coefficients were lower than reported in the other versions of the AKQoL. The construct validity of the AKQoL-NL seems reasonable, as we observed reasonable correlation with a dermatological-specific HRQoL instrument (Skindex-17) and poor correlation with frailty in general (GFI). The discriminative validity was high for patients with severe AK compared to those with mild or moderate disease severity.

\section{Feasibility}

The AKQoL was developed in Denmark and to date only the translation into Spanish has been validated in two studies $[9,10]$. Comparable to their results we also observed floor effects in items 6 and 8 [10], but we observed floor effects in 3 other items as well. This indicates that most patients do not have difficulties due to their sun-damaged skin or feelings of guilt regarding their sundamaged skin. These items may, however, be valuable for distinguishing a smaller subgroup of patients with a more severe impact of AK on their HRQoL. 


\section{Reliability}

As our results indicated poor internal consistency for the subscales, we would have liked to compare our results to the three other studies. However, the Danish as well as both of the Spanish studies only reported an overall Cronbach alpha, which ranged from 0.81 to 0.91 , which was higher than our overall estimate (0.64). Combining multiple correlated constructs (emotion, function, control, global) into one scale (AKQoL overall) leads to a high Cronbach alpha by definition [19]. As the correlation between the domains in our study was lower compared to the Danish and the Spanish studies, as a logical result the Cronbach alpha of the overall AKQoL was also lower. The Cronbach alpha per subscale provides information about the correlation between the items of one construct. A problem of the Cronbach alpha is that it increases with the number of items. The AKQoL has only 1-3 items per subscale, which leads to a low Cronbach alpha per subscale. Analysis of the item-rest correlation within the scales showed good performance of the items $(r>0.20)$ with the exception of item $8(r=0.15)$. Unfortunately, both the Spanish as well as the Danish study did not report a Cronbach alpha per subscale, and therefore we are unable to determine if the correlation between the items of one domain is lower or comparable to other studies. In accordance with both Spanish validation studies the testretest correlation was high $(>0.9)$.

\section{Validity}

In order to establish convergent validity, the AKQoL was previously compared to both the Dermatology Life Quality Index (DLQI) and the Skindex-29. We compared the AKQoL with the Skindex-17 which led to correlation coefficients (0.226-0.376) comparable to the Skindex-29 (0.344) [9]. The correlation with the DLQI was much higher $(>0.75)[10]$.

Our study adds information on divergent validity of the AKQoL. All previously performed studies did not compare the AKQoL with a generic HRQoL instrument. We have compared the AKQoL with the GFI, a general measure of frailty, which is an important determinant of generic HRQoL. As hypothesized, the GFI correlated very poorly with the AKQoL, indicating that the AKQoL specifically measures AK-related HRQoL impairment and does not measure poor well-being in general.

Our study also adds knowledge on the AKQoL performance in different severity groups. Both the Danish and the Spanish studies did not provide information on disease severity, possibly because it is difficult to count AKs [13]. Therefore, we assessed categories of AK count. We

Validity and Reliability of the AKQoL-NL observed that the mean AKQoL scores differed between patients with mild or moderate $\mathrm{AK}$ and patients with severe AK. Patients with mild AK may have little to no impaired HRQoL due to their AK, which may explain the proportion of floor effects.

\section{Strengths and Limitations}

Strengths of our study include the high response rate and the inclusion of a large number of patients both in a general hospital as well as in a tertiary referral center. This led to a diverse group of patients in whom it was possible to assess the performance of the AKQoL by disease severity. Another strength of our study is that we included the GFI in order to assess divergent validity.

A limitation of this study is that the translation is based on the English version of the AKQoL, and not the original Danish version. Another limitation is that no information was gathered on the patients refusing to participate in this study.

\section{Future Directions}

As we have shown that the mean AKQoL score is different for severe AK patients, future research could assess the responsiveness of the AKQoL (i.e., if the AKQoL changes with treatment response). This is needed to determine if the AKQoL can be used in clinical trials for therapy.

Since the debate on whether to treat or not to treat AK is still ongoing [20], the AKQoL may provide additional information for the individual patient to decide whether or not to treat. On a group level, on the other hand, it may help to identify patient groups eligible for treatment beforehand (e.g., elderly men with multiple AKs on the scalp).

Future studies should help to determine if the low internal consistency of the subscales is due to cultural differences or due to the design of the questionnaire. Therefore, the Cronbach alpha per subscale should be determined in future studies and, ideally, also that of the original Danish study.

\section{Conclusion}

Our study added important information on the validity of the AKQoL, showing that it has discriminative validity on disease severity and that it measures AK-specific HRQoL and not frailty in general. The internal consistency of the AKQoL-NL was poor, but the repeatability was excellent. The AKQoL-NL is a feasible and valid HRQoL instrument, but reliability is moderate and therefore the AKQoL-NL could be used as a tool to assess dis- 
ease-specific HRQoL in clinical and research setting. Therefore, interpretation of the domain scores must be done with great caution.

\section{Key Message}

The Dutch adaptation of the Actinic Keratosis Quality of Life Questionnaire (AKQoL-NL) is a feasible, moderately valid, and moderately reliable health-related quality of life questionnaire.

\section{Statement of Ethics}

All subjects provided informed consent.

\section{Disclosure Statement}

The authors have no conflict of interest or financial support to disclose.

\section{References}

1 Salasche SJ: Epidemiology of actinic keratoses and squamous cell carcinoma. J Am Acad Dermatol 2000;42:4-7.

-2 Frost CA, Green AC: Epidemiology of solar keratoses. Br J Dermatol 1994;131:455-464.

3 Harvey I, Frankel S, Marks R, Shalom D, Nolan-Farrell M: Non-melanoma skin cancer and solar keratoses. I. Methods and descriptive results of the south wales skin cancer study. Br J Cancer 1996;74:1302-1307.

$\checkmark 4$ Memon AA, Tomenson JA, Bothwell J, Friedmann PS: Prevalence of solar damage and actinic keratosis in a Merseyside population. $\mathrm{Br}$ J Dermatol 2000;142:1154-1159.

5 Naldi L, Chatenoud L, Piccitto R, Colombo P, Placchesi EB, La Vecchia C; Prevalence of Actinic Keratoses Italian Study Group: Prevalence of actinic keratoses and associated factors in a representative sample of the Italian adult population: results from the Prevalence of Actinic Keratoses Italian Study, 20032004. Arch Dermatol 2006;142:722-726.

-6 Both H, Essink-Bot ML, Busschbach J, Nijsten T: Critical review of generic and dermatology-specific health-related quality of life instruments. J Invest Dermatol 2007;127:27262739.

7 Nijsten TE, Sampogna F, Chren MM, Abeni DD: Testing and reducing Skindex-29 using Rasch analysis: Skindex-17. J Invest Dermatol 2006;126:1244-1250.

8 Esmann S, Vinding GR, Christensen KB, Jemec GBE: Assessing the influence of actinic keratosis on patients' quality of life - the AKQoL questionnaire. Br J Dermatol 2013;168:277283.
Longo Imedio I, Serra-Guillen C: Adaptation and validation of the Spanish version of the Actinic Keratosis Quality of Life questionnaire (AKQoL) (in English, Spanish). Actas Dermosifiliogr 2016;107:474-481.

10 Alarcon I, Vinding GR, Christensen K, Esmann S, Malvehy J, Puig S, Jemec GB: Spanish version of the Actinic Keratosis Quality of Life questionnaire. J Eur Acad Dermatol Venereol 2017;31:986-991-.

11 Flohil SC, van der Leest RJ, Dowlatshahi EA, Hofman A, de Vries E, Nijsten T: Prevalence of actinic keratosis and its risk factors in the general population: The Rotterdam Study. J Invest Dermatol 2013;133:1971-1978.

12 Weinstock MA, Bingham SF, Digiovanna JJ, Rizzo AE, Marcolivio K, Hall R, Eilers D, Naylor M, Kirsner R, Kalivas J, Cole G, Vertrees JE; Veterans Affairs Topical Tretinoin Chemoprevention Trial Group: Tretinoin and the prevention of keratinocyte carcinoma (basal and squamous cell carcinoma of the skin): a veterans affairs randomized chemoprevention trial. J Invest Dermatol 2012;132:15831590.

13 Lee KC, Lew R, Weinstock MA: Improvement in precision of counting actinic keratoses. $\mathrm{Br}$ J Dermatol 2014;170:188-191.
14 Bullinger M, Alonso J, Apolone G, Leplege A, Sullivan M, Wood-Dauphinee S, Gandek B, Wagner A, Aaronson N, Bech P, Fukuhara S, Kaasa S, Ware JE Jr: Translating health status questionnaires and evaluating their quality: The IQOLA Project approach. International Quality of Life Assessment. J Clin Epidemiol 1998;51:913-923.

-15 Sampogna F SA, Di Pietro C, Pagliarello C, Paradisi A, Tabolli S, Abeni D: Field performance of the Skindex-17 quality of life questionnaire: a comparison with the Skindex-29 in a large sample of dermatological outpatients. J Invest Dermatol 2013;133:104-109.

16 Steverink NS, J.P.J., Schuurmans H, van Lis M: Measuring frailty. Development and testing of the Groningen Frailty Indicator (GFI). Gerontologist 2001;41:236-237.

17 Peters LL, Boter H, Buskens E, Slaets JP: Measurement properties of the Groningen Frailty Indicator in home-dwelling and institutionalized elderly people. J Am Med Dir Assoc 2012; 13:546-551.

18 Tennvall GR, Norlin JM, Malmberg I, Erlendsson AM, Haedersdal M: Health-related quality of life in patients with actinic keratosis - an observational study of patients treated in dermatology specialist care in Denmark. Health Qual Life Outcomes 2015;13:111.

19 Streiner DL, Norman GR: Health Measurement Scales: A Practical Guide to Their Development and Use. Oxford, Oxford University Press, 2003.

20 Werner RN, Sammain A, Erdmann R, Hartmann V, Stockfleth E, Nast A: The natural history of actinic keratosis: a systematic review. Br J Dermatol 2013;169:502-518. 